\title{
Dem numerical modeling of longwall extraction of coal in "Mysłowice" colliery
}

\author{
Grzegorz Smolnik \\ Silesian University of Technology, Gliwice, Poland
}

\begin{abstract}
SUMMARY: The paper presents the results of the numerical DEM analysis of the extraction of coal by longwall system both with roof caving and with hydraulic backfilling. The exploitation of the most productive in the basin coal seam 510 was undertaken by the Mysłowice colliery in a very rockburst prone strata at the depth of app. $600 \mathrm{~m}$. The successful extraction with backfilling of the last longwall panel in the section of the mine was a key to any other future mining activity in the area as the stress concentration and resulting rockbursts would prevent it otherwise. The deformation of boreholes measurements as well as geophysical monitoring was widely applied by the mine. The UDEC numerical model of the extensive section of the mine was built and all the extraction of coal activities ranging the period of nearly 45 years were simulated. The changes of the state of stress and strain as well as movements of the blocks in the vicinity of the longwall workings were analyzed. The strain changes in the numerical model were determined at the positions corresponding to the location of borehole measurements in-situ. The rate of advance and productivity of the longwall face turned out to be directly related to the changing geomechanical conditions just as they were determined by the numerical simulation.
\end{abstract}

Keywords: longwall mining, hydraulic backfill, numerical modelling, Distinct Element Method, UDEC

\section{INTRODUCTION}

The most productive in the whole Upper Silesian Coal Basin seam has been extracted in Myslowice colliery for many years. The average seam thickness in that mine was about $9.5 \mathrm{~m}$ and so it was exploited in stages (slices) by longwall mining methods both with roof caving and hydraulic backfilling of the goaf area. The stoping was undertaken simultaneously both in the eastern and in the western part of the mine. The longwall extraction commenced at the borders of mine lease area and gradually, with each next panel, it was moved towards the central portion of the seam. Finally, the strip of a width of $200-320 \mathrm{~m}$ was left surrounded by the goaf from each side. The successful extraction with backfilling of the last longwall panel in the section of the mine was a key to any other future mining activity in the area as the stress concentration and resulting rockbursts would prevent it otherwise. Not only the exploitation of the above lying layers of seam 510 would have been impossible but the plans for stoping in seam 501 of the average thickness of $8 \mathrm{~m}$ laying above and separated from the 510 seam by the $2.5 \mathrm{~m}$ layer of shale might have also been abandoned.

Challenging, mainly due to the rock burst hazard extraction of the mining panel $411 \mathrm{~b}$ resulting in the distressing of the coal seams and rocks in its vicinity was of a huge importance for the mine. 
Numerical modelling allows to investigate the response of the rock mass subjected to extensive stoping in a way far beyond the other analytical methods. Nevertheless both the determination of the rock properties in the laboratory and the in-situ measurements of the rock mass properties are very welcomed sources of data which make the modelling process useful for the mining company. Without those the boundary and initial condition determination as well as the material properties input is much less reliable. As the extensive program of measurements of the deformations of the boreholes was undertaken in the mine and seismic methods including seismic tomography, micro-gravimetry, seismic acoustic techniques were deployed for years the challenge to create a model of a significant portion of the mine and the simulation of the exploitation of coal carried out for decades in the area was undertaken.

The numerical modelling of mine strata and the computer simulation of longwall mining with hydraulic backfilling and roof caving was done using the two-dimensional distinct element method code $U D E C$. UDEC is based on a Lagrangian calculation scheme that is wellsuited to model the large movements and deformations of blocky systems. This code is extremely useful in the simulation and analysis of the effect of rock joints, faults, bedding planes, etc. on the behaviour of rock masses and the stability of excavations and structures built in rocks or on rocks. It has been used successfully at the Rock Mechanics Laboratory of the Silesian University of Technology for years to study the behaviour of mine strata affected by the influence of longwall mining (see for example Kwaśniewski, 2008).

\section{NUMERICAL MODELLING OF MINE STRATA}

\subsection{Structural model of mine strata}

In an attempt to study the behaviour of the mine strata in the vicinity of the longwall panel in the high stress conditions, a numerical model of a large part of the rock mass in the vicinity of longwall panel $411 \mathrm{~b}$ in coal seam 510 in the Mysłowice Colliery was built. This was a twodimensional rectangular model $1500 \mathrm{~m}$ long and $750 \mathrm{~m}$ high. The upper boundary reached the land surface and the floor of the seam 510 was at the depth of $592 \mathrm{~m}$ (Figure 1).

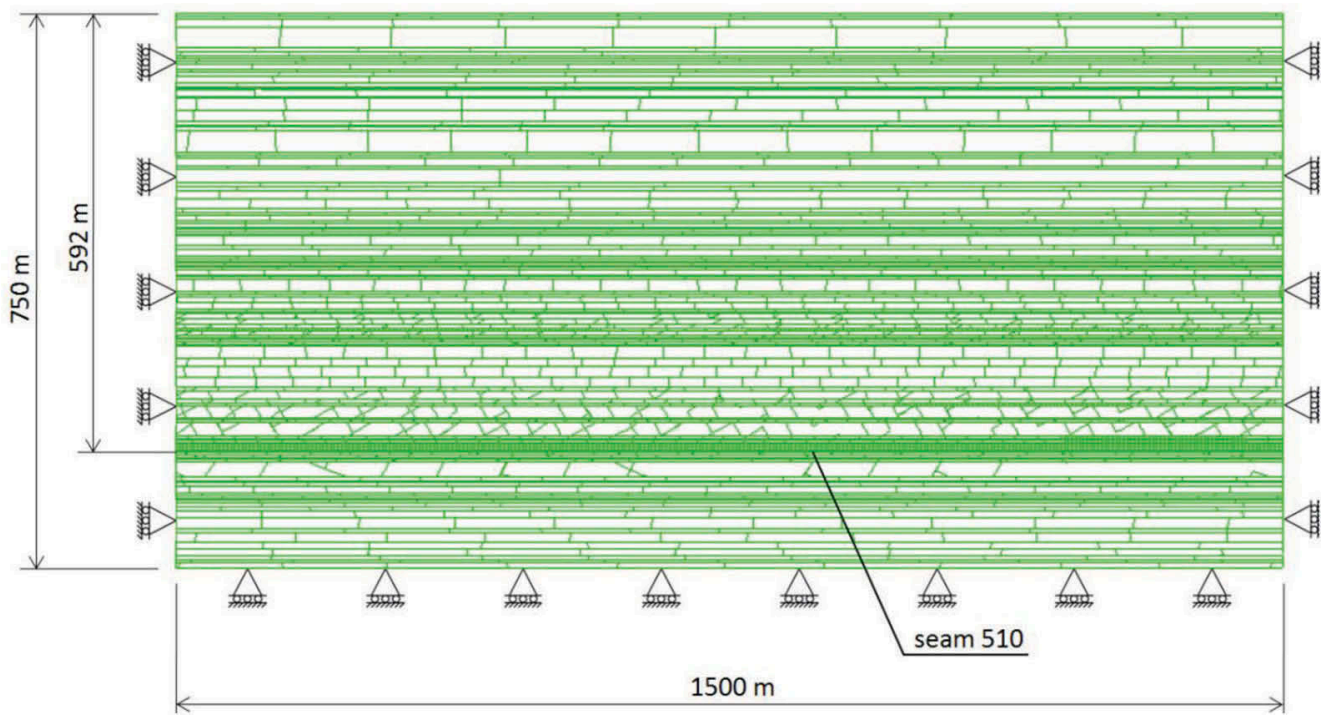

Figure 1. Structural model of mine strata in the vicinity of coal seam 510 in longwall panel $411 \mathrm{~b}$ in the Mysłowice Colliery: 112 rock layers (including 9 coal seams and a soil (clay) layer at the upper boundary). 
Above and beneath the seam 510 one hundred and nine rock layers (including eight coal seams) of a thickness from 1.9 to $29.0 \mathrm{~m}$ were modeled. These were the layers built of different varieties of sandstones, mudstones, sandy shales, clayey shales, coaly shales and coal. On the land surface of the mining area (upper boundary of the model) there was also one soil layer (clay) of the thickness $2.5 \mathrm{~m}$ and it was likewise modeled.

Individual rock layers, separated by parallel contacts (joint system $\mathrm{I}, \alpha_{1}=0^{\circ}$ ), were divided into blocks by joint systems oriented at angles $\alpha_{2} \approx 30^{\circ}$ and $\alpha_{3} \approx 120^{\circ}$ (joint system II) and $\alpha_{4} \approx 60^{\circ}$ and $\alpha_{5} \approx 160^{\circ}$ (joint system III)relative to joint system I. It was only the to-be-mined parts of coal seams that were divided into rectangular blocks by a system of joints oriented to the bedding planes at an angle $\left(\alpha_{6}\right)$ of $90^{\circ}$ (joint system IV). All these discontinuities were the so-called fictitious joints, i.e. the joints whose mechanical properties were the same as the mechanical properties of the rock material. Such joints may become active only if stresses reach either the tensile or shear ultimate strength at a given location. The decision to divide the model into blocks with fictitious joints was taken deliberately in order to be on the conservative side and not to facilitate the fracturing of the modeled mine strata.

Four systems of joints of different orientations divided the model of the mine strata into 4101 fictitious blocks of an average size of $274.3 \mathrm{~m}^{2}$, which contacted each other at 41,292 contacts. The blocks were discretised into finite-difference triangular elements. The number of deformable zones and the number of gridpoints were equal to 32,079 and 37,837, respectively (Table 1).

\subsection{Constitutive models and material parameters}

The strain-softening (elastic-brittle-plastic) constitutive model with ultimate and residual strength defined by the modified Mohr-Coulomb strength criterion was assigned to the rock blocks. The following material parameters occur in this model: bulk modulus $(K)$, shear modulus $(G)$, angle of internal friction $(\varphi)$, angle of residual internal friction $\left(\varphi_{r}\right)$, cohesion $(c)$, residual cohesion $\left(c_{r}\right)$, tensile strength $\left(\sigma_{T}\right)$, angle of dilatancy $(\psi)$ and angle of residual dilatancy $\left(\psi_{r}\right)$. Values of these parameters for different rocks that build the mine strata in the vicinity of seam 510 in longwall panel $411 \mathrm{~b}$ in the Myslowice Colliery are listed in Table 2. Values of the remaining parameters were calculated using the following relationships: $c_{M r}=0.1 c, \varphi_{r}=2 / 3 \varphi, \psi=0.5 \varphi$ and $\psi_{r}=2 / 3 \psi$.

The model adopted makes it possible to describe any arbitrary non-linear behaviour of rock material in the post-failure domain. In contrast to the Coulomb model of plasticity, where cohesion, friction and dilation remain constant, in the brittle-plastic model these quantities are certain functions of plastic shear strain $\left(\mathrm{e}^{\mathrm{ps}}\right)$. When modelling the softening behaviour of rocks in the post-shear-failure domain, it was assumed in the present study that: (i) these functions have a piecewise-linear form and (ii) the cohesion, angle of internal friction and angle of dilatancy drop to their residual values at $\mathrm{e}^{\mathrm{ps}}=0.001$. A mechanical model capable of: (i) normal and shear elastic deformation, (ii) dilation, (iii) irreversible slip with displacement softening and (iv) tensile fracturing, was assigned to the joints between blocks.

It was assumed that the joints behave in a linear manner in the pre-failure domain and slip is governed by the Coulomb criterion. The adopted values of the mechanical parameters of

Table 1. Basic structural parameters of the model of mine strata.

\begin{tabular}{ll}
\hline Parameter & Value \\
\hline Model dimensions, L $[\mathrm{m}] \times \mathrm{H}[\mathrm{m}]$ & $1500.0 \times 750.0$ \\
Number of rock layers, including coal seams & 112 \\
Number of fictitious blocks & 4101 \\
Block size $\left[\mathrm{m}^{2}\right]$ : min./max./av. & $0.23 / 7868 / 274.3$ \\
Number of fictitious contacts & 41,292 \\
Number of finite-difference zones & 32,079 \\
Number of gridpoints & 37,837 \\
\hline
\end{tabular}


Table 2. List of rocks and soil distinguished in the mine strata in the Mysłowice Colliery and values of their mechanical parameters.

\begin{tabular}{lllllll}
\hline Rock type & $\rho \mathrm{kg} \mathrm{m}^{-3}$ & $K_{M} \mathrm{MPa}$ & $G_{M} \mathrm{MPa}$ & $c_{M} \mathrm{MPa}$ & $\varphi$ deg & $\sigma_{T M} \mathrm{MPa}$ \\
\hline Coarse-grained sandstone & 2475 & 5460 & 3926 & 1.56 & 38 & 0.11 \\
Medium-grained sandstone & 2500 & 5556 & 4167 & 1.79 & 39 & 0.13 \\
Fine-grained sandstone & 2525 & 5469 & 4449 & 2.03 & 40 & 0.15 \\
Very fine-grained sandstone & 2550 & 5392 & 4741 & 2.20 & 42 & 0.17 \\
Sandy mudstone & 2570 & 5655 & 3893 & 2.14 & 38 & 0.21 \\
Mudstone & 2590 & 5455 & 3673 & 2.17 & 36 & 0.22 \\
Sandy shale & 2610 & 5247 & 3455 & 1.41 & 34 & 0.14 \\
Sandy-clayey shale & 2600 & 4938 & 3252 & 1.06 & 34 & 0.11 \\
Hard clayey shale & 2625 & 4487 & 2823 & 1.17 & 33 & 0.13 \\
Clayey shale & 2650 & 4000 & 2400 & 0.89 & 32 & 0.10 \\
Soft clayey shale & 2400 & 2083 & 1190 & 0.47 & 29 & 0.08 \\
Coaly shale & 2200 & 1852 & 980 & 0.24 & 26 & 0.04 \\
Coal & 1400 & 1667 & 5563 & 0.64 & 30 & 0.22 \\
Clay & 1950 & 15 & 7 & 0.008 & 20 & 0.0008 \\
\hline
\end{tabular}

Explanations: $\rho$ - bulk density, $K_{M}$ - rock mass bulk modulus, $G_{M}$ - rock mass shear modulus, $c_{M}$ - rock mass cohesion, $\varphi$ - angle of internal friction, $\sigma_{T M}$ - rock mass tensile strength.

this Coulomb slip (area contact) model of joints, which include: coefficients of normal and shear stiffness $\left(k_{n}\right.$ and $k_{s}$, respectively), friction angle $\left(\varphi_{j}\right)$, cohesion $\left(c_{j}\right)$, tensile strength $\left(\sigma_{T j}\right)$ and dilation angle $\left(\varphi_{j}\right)$, were obviously different for different rocks; in Table 3 only the maximum and the minimum values of these parameters are given. As was mentioned above, the mine strata were divided into blocks by the so-called fictitious joints; therefore, the assumption was made that $c_{j}=c_{M}, \varphi_{j}=\varphi$ and $\sigma_{T j}=\sigma_{T M}$.

\subsection{Physical model of hydraulic backfill}

To model the hydraulic backfill the approach proposed by Clark, 1991 was followed. The double-yield constitutive model was chosen in which permanent volume changes caused by the application of isotropic pressure are taken into account by including, in addition to the shear and tensile failure envelopes in the strain softening/hardening model, a volumetric yield surface (or "cap"). For simplicity, the cap surface, defined by the "cap pressure" $p_{c}>0$, is independent of shear stress; it consists of a vertical line on a plot of shear stress versus mean stress (ITASCA, 1996). The hardening behaviour of the cap pressure is activated by volumetric plastic strain, and follows a piecewise-linear law prescribed in a user-supplied table. According to results obtained by Clark the cap pressure position is described by the formula:

$$
c_{p}=W\left[\frac{\varepsilon^{p v}}{H-\varepsilon^{p v}}\right]^{\alpha}+c_{p}^{0}
$$

Table 3. Values of the mechanical parameters of discontinuities in the model of the mine strata (Fictitious joints between rock and soil blocks).

\begin{tabular}{cccccr}
\hline$k_{n} \mathrm{MPa} \mathrm{m}^{-1}$ & $k_{s} \mathrm{MPa} \mathrm{m}^{-1}$ & $c_{j} \mathrm{MPa}$ & $\varphi_{j} \mathrm{deg}$ & $\sigma_{T j} \mathrm{MPa}$ & $\psi_{j} \operatorname{deg}$ \\
\hline $14.4-8000$ & $5.5-3296$ & $0.0008-2.2$ & $20-42$ & $0.004-0.22$ & $10-21$ \\
\hline
\end{tabular}

Explanations: $k_{n}$ - normal stiffness coefficient, $k_{s}$ - shear stiffness coefficient, $c_{j}-$ cohesion, $\varphi_{j}-$ friction angle, $\sigma_{T j}-$ tensile strength, $\psi_{j}$ - dilation angle. 
Table 4. Values of the mechanical parameters of the double-yield model of the backfill.

\begin{tabular}{llllllll}
\hline \multicolumn{7}{c}{ Volumetric yield } \\
\hline Strain $\varepsilon^{\mathrm{pv}}$ & 0.00 & 0.02 & 0.04 & 0.06 & 0.08 & 0.10 & 0.12 \\
Pressure $c_{\mathrm{p}}$ & 0.01 & 0.2 & 0.8 & 1.3 & 3.5 & 5.5 & 8.5 \\
Strain $\varepsilon^{\mathrm{pv}}$ & 0.14 & 0.16 & 0.18 & 0.20 & 0.22 & 0.24 & 0.28 \\
Pressure $\mathrm{c}_{\mathrm{p}}$ & 11.5 & 19.0 & 34.0 & 50.0 & 80.0 & 170.0 & 540.0 \\
\hline \multicolumn{7}{c}{ Shear yield } \\
\hline Strain $\varepsilon^{\mathrm{pv}}$ & 0.0 & & 0.1 & & \\
Cohesion c, MPa & 0.004 & & 0.005 & & \\
Internal friction angle $\phi$, deg & 28 & & 8 & & \\
Dilation angle $\Psi$, deg & 7 & & 8 & & \\
\hline
\end{tabular}

where $C_{p}{ }^{\circ}$ denotes initial cap pressure and $W, H$ and $\alpha$ are constants for a given material. The relationship $c_{p}=f\left(e^{p v}\right)$ is given in a Table 4 , and cohesion, internal friction angle and dilation angle changes as a function of plastic shear strain are also listed there.

The distinct element method code $U D E C$ is able to simulate the excavation of the seam with backfilling in a quite realistic manner. It is performed by changing the seam blocks to a null material, and backfilled by changing the null material to a double-yield material.

\subsection{Model of the longwall support}

The support of the 2.6-m-high longwall face in seam 510 was modelled using a 10-element support member. The maximum load-bearing capacity of the model of the longwall support $\left(\mathrm{P}_{\max }=1.03 \mathrm{MN}\right)$ and axial stiffness coefficient $(30 \mathrm{MN} / \mathrm{m})$ were equal to the nominal loadbearing capacity and stiffness of the two-leg mechanised shield support FAZOS-21/31Op that was used in longwall $411 \mathrm{~b}$ in the Myslowice Colliery. The model of the support was positioned at a distance of $0.45-0.75 \mathrm{~m}$ from the coal face and supported the roof over a length of $3.5 \mathrm{~m}$.

\subsection{Boundary and initial conditions}

The horizontal displacement of the model was fixed to zero at the left and right vertical boundaries and no vertical displacement boundary condition was applied to the bottom boundary of the model. The top of the model was left unstressed, as it was assumed to represent the land surface of the mining terrain.

When initializing the primary state of stress in the model it was assumed that the vertical stress in rock masses results from body forces and is determined by the depth and bulk density of the overlying rocks and coal, while the horizontal stress - according to the classic solution based on the theory of elasticity - is a fraction of the vertical stress governed by Poisson's ratio. After stepping the model to initial equilibrium, which required 3000 calculation steps, the primary state of stress was established in the model with the maximum principal stress in the region of the future setup entry in seam 510 equal to $14.38 \mathrm{MPa}$ and the minimum principal stress in the same area equal to $6.18 \mathrm{MPa}$.

Only then was the computer simulation of longwall mining and investigation of the behaviour of mine strata affected by mining begun.

\section{COMPUTER SIMULATION OF THE EXTRACTION OF MULTIPLE SEAMS IN THE MYSLOWICE COLLIERY}

\subsection{Longwall mining in 9 seams extracted over the period of 45 years}

Before the detailed study of changes in the state of stress, strain and displacements of mine strata that accompany the extraction of longwall panel $411 \mathrm{~b}$ commenced all the mining of 
coal in the area, in 9 coal seems, which took place over the period of 45 years was simulated. Progressive extraction of two seams(405 and 416) with roof caving and seven (418, 501/1, 501/ $2,501 / 3,510 / 1,510 / 2,510 / 3$ ) with backfilling was simulated in the same order as it was done in the mine. In each mining simulation stage, the seam was extracted over a length of $25.0 \mathrm{~m}$ by removing five blocks $5.0 \mathrm{~m}$ long. Each time the constitutive model of coal was replaced by the so-called null model and then the blocks were either deleted (roof caving) or their constitutive model was changed to the double-yield (backfilling). When an extraction in one seam took place in the same quarter of the given year as the extraction in another longwall panel in a different coal seam the simulation of those exploitations was done simultaneously.

As a result of mining, very significant changes in the stress field in the vicinity of the mined seam occurred. A substantial redistribution of stresses, including both a change of the directions of the principal stresses and a change in stress values took place. The maximum principal stresses $\left(\sigma_{1}\right)$ that were originally oriented vertically assumed a horizontal direction above and below the mined-out section of the seam, whereas the minimum principal stresses $\left(\sigma_{3}\right)$ changed their direction from horizontal to vertical. Both these components of the stress tensor decreased significantly in this region; at the same time, the minimum principal stresses became tensile in many places.

Extensive exploitation of 9 coal seams resulted in the fracturing of nearly two thousand three hundred and thirteen contacts between the initially fictitious blocks; this number is about $5.6 \%$ of the total, 41,292 , number of contacts. The number of fractured contacts, i.e. the contacts that do not convey normal and/or shear forces, increases as the mining progresses.

The size of the area where rocks underwent failure due to excessive shear or tensile stresses reached $206,900 \mathrm{~m}^{2}$, it was $18.4 \%$ of the total, $1125,000 \mathrm{~m}^{2}$, area of the model being investigated (Figure 2). The area of failed rocks is particularly large in the strata lying above extracted seams, it reaches the upper boundary of the model in some places and, moreover, it extends beyond the edges of the extraction area. In many cases rocks located at a significant distances from the longwall panels underwent damage. Failure of rocks also occurred in layers directly beneath the longwall panels.

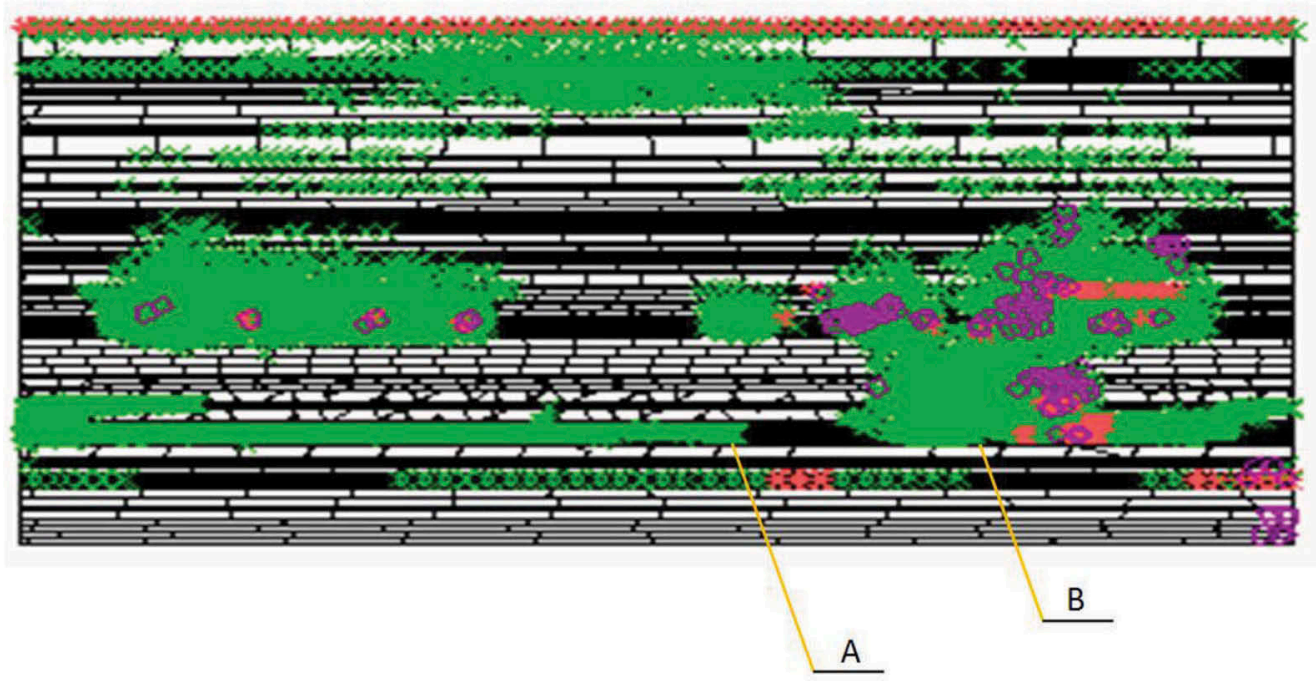

Figure 2. Failure of rocks due to excessive shear stresses (displayed in light red when the state of stress is at the yield surface and in green when yielded in the past) or tensile stresses (denoted by circles in magenta) after nine seams had been extracted over 45 years and before the longwall panel $411 \mathrm{~b}$ exploitation took place. (A - position of the start of the simulation of the extraction of coal in longwall face $411 \mathrm{~b}, \mathrm{~B}-$ recovery room of longwall face $411 \mathrm{~b}$ ). 
The extent of the fractured zones in the rock mass is much more profound in the vicinity of the longwall panels extracted with roof caving, when compared to those extracted with backfilling.

\subsection{Extraction of longwall panel $411 \mathrm{~b}$ with hydraulic backfilling in a very rock burst prone area}

The first months of extraction of longwall panel $411 \mathrm{~b}$ resulted in an increased seismicity in the area and when a few very strong tremors occurred in the vicinity of the panel its operation was halted for several months. The mine suffered in the past form the strong rock bursts/coal bumps resulting also in some fatalities so the State Mining Authority demanded special extensive monitoring measures to be adopted before the permission to resume the mining of coal in longwall panel $411 \mathrm{~b}$ could be issued. The deformation of boreholes measurements as well as geophysical monitoring was widely applied by the mine. It is this stage of exploitation when the detailed numerical analysis of the extraction of coal in longwall panel $411 \mathrm{~b}$ with hydraulic backfilling was commenced.

Progressive extraction of seam 510 in longwall panel $411 \mathrm{~b}$ was simulated over a length of $300 \mathrm{~m}$ starting from the position $\mathrm{x}=845 \mathrm{~m}$ and advancing towards the right boundary of the model (see Figure 2). At the first simulation stage one 5.0-m-long block was removed from the seam and the support members simulating the shields were placed. At the second simulation stage next 5.0-m-long block was removed from the seam and the roof support was moved five meters. At the third simulation stage the constitutive model of the next block was changed to null, roof support moved five metres and the hydraulic backfill was introduced by changing the constitutive model of a block where roof support was placed at the first stage, to double-yield.

At each of the subsequent 57 mining simulation stages, one 5.0-m-long block was removed from the seam, the model of the shield was moved and a hydraulic backfill was placedaccordingly. Next, 2000 calculation steps were executed. The last two stages simulated the operation in the recovery room of the longwall i.e. backfilling of the area directly behind the roof support units, removing the shields and complete backfilling of the recovery room.

\section{DISCUSSION OF THE SIMULATION RESULTS}

Simulation of over forty years of extensive extraction of coal revealed the mining-induced changes in the state of strain and stress in rock blocks and the location and size of the areas where rock material failed in shear or tension and underwent transition into the post-failure range in the direct vicinity of the longwall panel $411 \mathrm{~b}$.

Initially uniform state of stress has been altered significantly; the whole $300 \mathrm{~m}$ long portion of the seam 510 to-be-mined-out by longwall panel $411 \mathrm{~b}$ can be divided into two parts (halves) of approximately the same length.

Major principal stress values in the first $130-150 \mathrm{~m}$ portion of the seam increased from the initial values of 14.5 MPa to 18-19 MPa. In the second half of the seam $\sigma_{1}$ values decreased quite rapidly to about $8 \mathrm{MPa}$ and closer to recovery room slightly increased but to not more than $10 \mathrm{MPa}$.

Extraction with roof-caving of $3.2 \mathrm{~m}$ thick seam 416laying $60 \mathrm{~m}$ above, which took place a year and a half before was a major contributor to those changes. It was also a cause of the failure of considerable parts of the rock mass between the seams 416 and 510 and even the layer of shale directly beneath the seam 510. Noteworthily the coal of the seam 510 due to its high strength did not yield and remained in the pre-failure, elastic range and thus was able to accumulate the elastic strain energy.

When the simulation of the operation of longwall panel $411 \mathrm{~b}$ began the state of stress, strain and displacement was monitored in its vicinity and the major principal stress changes in a coal block directly adjacent to the shearer, armoured face conveyor and shields (i. e. longwall face) are shown, as an example, in Figure 3. Horizontal axis represents the position of the longwall face; abscissa $x=0 \mathrm{~m}$ gives the position of the face at the start of the 


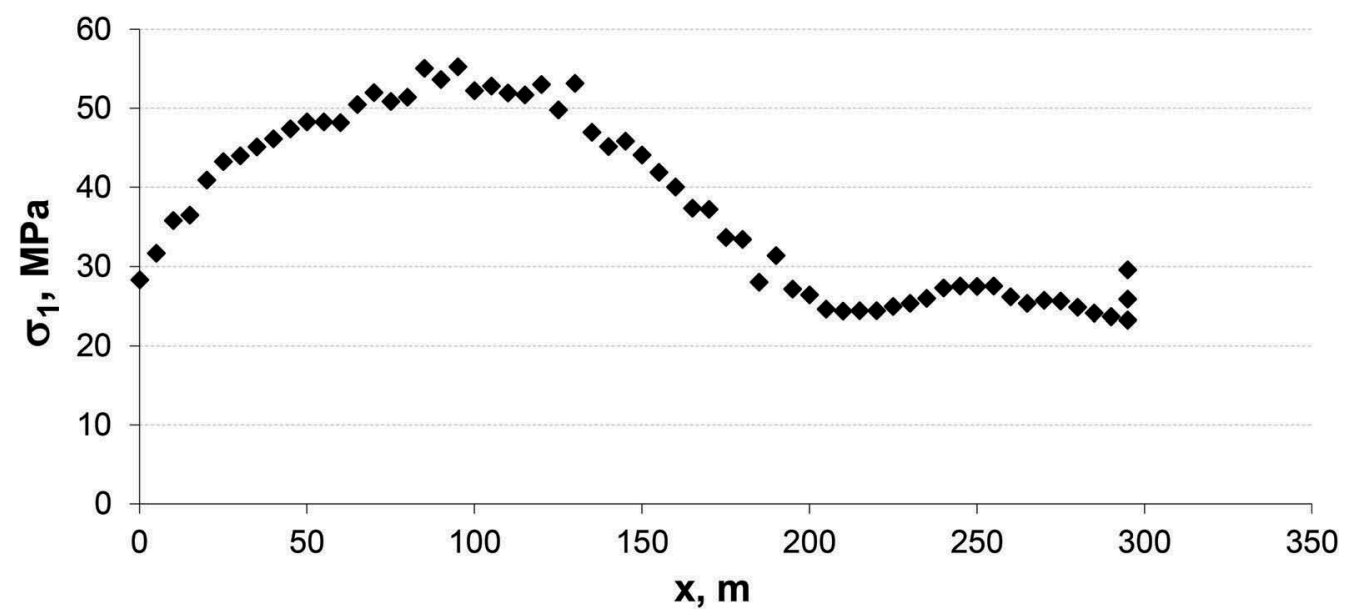

Figure 3. Distribution of the maximum values of the major principal stress in seam 5107 ahead of the longwall face corresponding to different lengths of the mined-out section of the seam.

simulation of the extraction of coal in longwall face $411 \mathrm{~b}$ (point $\mathrm{A}$ in Figure 2) and $\mathrm{x}=295 \mathrm{~m}$ represents the final position of the face reaching the recovery room (point $\mathrm{B}$ in Figure 2).

After the commencement of the extraction of coal $\sigma_{1}$ values increase from $28 \mathrm{MPa}$ to more than $55 \mathrm{MPa}$ for the first $100 \mathrm{~m}$ of the seam and then the major principal stress decreases gradually. When the longwall face is at the position $\mathrm{x} \approx 200 \mathrm{~m} \sigma_{1}$ values drop to about $25 \mathrm{MPa}$. The changes of major principal stress in the final $100 \mathrm{~m}$ are not significant, $\sigma_{1}$ values are in a range of $24.5-27.5 \mathrm{MPa}$.

The above mentioned changes of the major principal stress values are only one of the indicator of the geomechanical conditions in which extraction of the panel $411 \mathrm{~b}$ took place.

High $\sigma_{1}$ values in the first half of the extracted portion of the seam 510 are accompanied by substantial movement of rock blocks, both located in the roof but also in the floor of the seam, towards the working area. There are also significant closures of the joints in the gob and compaction of the hydraulic backfill. Directly above the coal face there are considerable separations and shear displacement of blocks resulting in a significant loading of the longwall shields.

Conditions in the second half of the extracted portion of the seam 510 are appreciably different. Destressing due to the roof-caving longwall extraction of the above laying seam 416 although did not result in failure of coal in the seam 510 but did cause the adjacent layers of shales (manly clayey and sandy shales) to reach the post-failure regime of their behavior and very significant drop of $\sigma_{1}$ values. In a result there are much smaller movements of rock blocks towards the working area; the displacement of blocks in the roof decreases so substantially that the floor up-heave becomes more pronounced. Closures of the joints in the gob, compaction of the hydraulic backfill, shear and normal displacements (separations) in the roof above the longwall face are also much smaller. Not surprisingly, loading of the hydraulic powered roof support units (shields) is likewise significantly smaller.

The results of the numerical simulation were confirmed by the conditions experienced in the longwall face and as an example, monthly advance of the longwall face $411 \mathrm{~b}$ is given in Figure 4.

During the first five months of the exploitation of the panel $411 \mathrm{~b}$ the monthly advance rate was quite regular but in the final portion of the seam it increased twice. The beginning of the significant increase of the advance rate (December) was achieved when the longwall face reached the position $\mathrm{x} \approx 120$-135 $\mathrm{m}$ corresponding to the location where major principal stress values as well as shear and normal displacements of blocks and joints and shields loading started do decrease. 


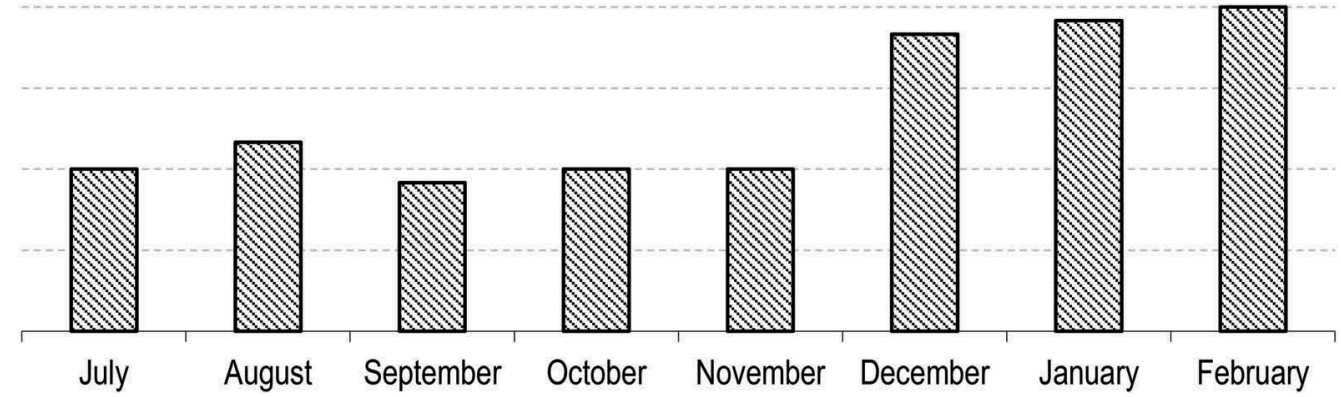

Figure 4. Average monthly advance rates of longwall panel 411b.

Displacements and strains were monitored at ten positions in the model which corresponded to the spots where extensometers were placed in drilled holes in the mine.

The results obtained were very similar in all the places of monitoring which were located close (both in vertical and horizontal direction) to the longwall face. Recorded displacements and strains at sites positioned far away from the active longwall were much smaller and the pattern of changes was not so regular and was different from that which is common to the points located in the vicinity of the longwall panel.

As an example of the recorded data Figure 5 displays the general pattern of the behavior of roof layers above the longwall face with hydraulic backfill as revealed by the numerical simulation. The actual measurements results are of the same nature although not so regular and

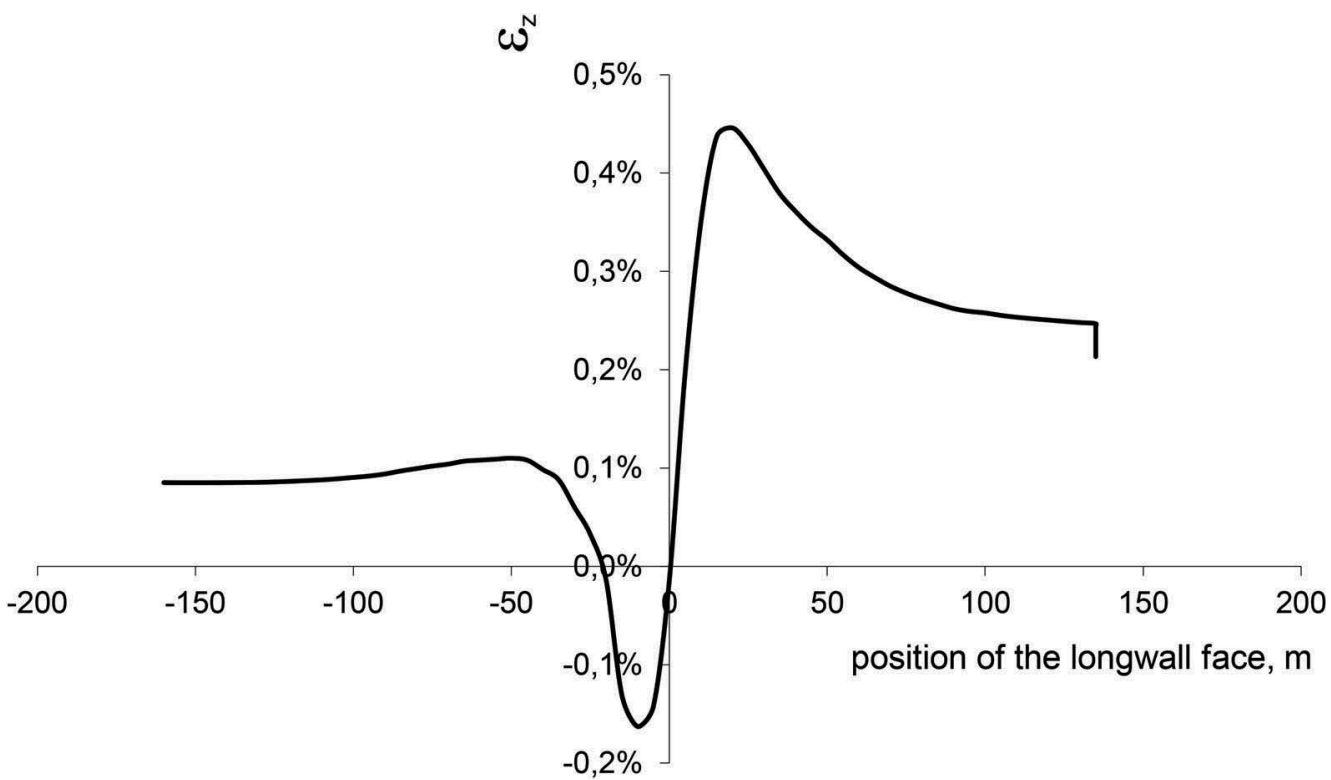

Figure 5. Vertical strain $\left(\varepsilon_{z}\right)$ changes induced by the longwall face $411 \mathrm{~b}$ passing beneath a D1 monitoring station recorded in a numerical model. D1 monitoring station position in the model, about $16 \mathrm{~m}$ above the extracted seam, corresponded to the D1 measurement site location in the Myslowice colliery rock mass. 
not in every monitoring station. The reason for this is to be believed the difficulty to conduct measurements in a very challenging environment of the underground coal mine.

Horizontal axis gives the position of the longwall face relative to the position of the monitoring point. Negative values mean that the longwall face is located in front of the monitoring spot, positive values indicate that the longwall face passed beneath the recording point and moves away from it. Vertical axis displays vertical strain $\left(\varepsilon_{z}\right)$, negative values mean shortening, positive - elongation.

Figure 5 display the strain values from the time when the longwall face was located $160 \mathrm{~m}$ ahead and till the time when it was $135 \mathrm{~m}$ behind the position of D1 monitoring station.

Initially, the strain increasers slightly, about $0.02 \%$ and when the longwall face is about $45 \mathrm{~m}$ away it suddenly decreases and becomes negative when the longwall face approaches D1 monitoring station at a horizontal distance of $20 \mathrm{~m}$. Then the rapid increase of the shortening strains follows till the minimum value (of about $-0.16 \%$ ) is reached when the approaching longwall face is $10 \mathrm{~m}$ in front of the monitoring point. Strain during the movement of the longwall face from that point to the place directly beneath the monitoring station decreases and assumes $0.0 \%$ value when the longwall face passes under the monitoring point position. The subsequent movement of the longwall face, moving away from the monitoring station location induces positive strain which reaches its maximum (about $0.45 \%$ ) when the horizontal distance from the longwall face to the monitoring point is $20 \mathrm{~m}$.

After the maximum value is reached the strain decreases, at a declining rate to $0.24 \%$. Vertical portion of the curve $\varepsilon_{\mathrm{z}}=\mathrm{f}(\mathrm{x})$ for $\mathrm{x}=135 \mathrm{~m}$ represents the reduction of strain during the halt of the longwall in a recovery room. The above mentioned pattern of strain changes obtained in the numerical simulation is very similar to the in-situ strain changes described in literature (e.g. see Knothe, 1984).

\section{SUMMARY}

Using the distinct element code $U D E C$, numerical model of a large part of a rock mass was built. This was two-dimensional model of the strata in the vicinity of coal seam 510 in longwall panel $411 \mathrm{~b}$, extracted with hydraulic backfilling, at the depth of app. $600 \mathrm{~m}$ in the Mysłowice Colliery in the Upper Silesian Coal Basin, Poland.

Before the detailed simulation of the extraction of longwall panel $411 \mathrm{~b}$ in a very rock-burst prone conditions was started, all the mining of coal in the area, in 9 coal seems, which took place over the period of almost 45 years was simulated. Progressive extraction of two seams with roof caving and seven with backfilling was simulated in the same order as it was done in the mine.

When analyzing the computation results, discontinuous deformations of rock masses in the vicinity of the longwall faces were investigated with particular attention being paid to the formation of the caving zone above the seam being mined and loading of the backfill and longwall support, and to the fracturing, separation and heave of the floor strata. Normal and shear displacements along joints were monitored carefully, with the main focus on joint slip and separation. Mining-induced changes in the state of strain and stress in rock blocks and the location and size of the areas where rock material failed in shear or tension and underwent transition into the post-failure range were determined as well.

Displacements and strains were monitored at ten positions in the model which corresponded to the spots where extensometers were placed in drilled holes in the mine.

Strain changes obtained in the numerical simulation are very similar to the published results of the in-situ strain changes measurements in the roof layers located above longwall workings.

The results of the numerical simulation were confirmed by the conditions experienced in the 411 b longwall face.

The rate of advance and productivity of the longwall turned out to be directly related to the changing geomechanical conditions just as they were determined by the numerical simulation. 
Although the induced-seismicity level in the $411 \mathrm{~b}$ longwall panel was high no strong (dangerous) tremor occurred and the extraction of the whole mining panel $411 \mathrm{~b}$ was executed safely.

The successful extraction with backfilling of the last longwall panel in that section of the colliery in the near-floor slice of seam 510 did open a way for mining activities in the area in the overlaying layers of the seams 510 and 501 of the total thickness of $15 \mathrm{~m}$ or even more. UDEC - DEM numerical simulation proved to be a useful tool supporting the assessment of the rock mass behavior when extensive longwall mining with roof caving and hydraulic backfilling operations are undertaken.

\section{ACKNOWLEDGMENT}

The author also expresses gratitude to the National Agency for Academic Exchange of Poland (under the Academic International Partnerships program, grant agreement PPI/APM/ 2018/1/00004) for financial support of the internship at Montanuniversität in Leoben, Austria, which enabled the execution of a part of the work.

\section{BIBLIOGRAPHY}

Clark I.H., 1991, The cap model for stress path analysis of mine backfill compaction processes. Computer Methods and Advances in Geomechanics (Proceedings of the 7th International Conference, Cairns, Australia, May 1991), Rotterdam, A. A. Balkema, Vol. 2, pp. 1293-1298.

Itasca Consulting Group, Inc., 1996, UDEC 3.0 User's Manual (3 vols), Minneapolis.

Matwiejszyn, A. \& M. Ptak: Measurements of borehole deformations for assessment of rockburst hazard. In Seismogenic Process Monitoring (H. Ogasawara, T. Yanagidani \& M. Ando, eds), pp. 63-74. A. A. Balkema, Rotterdam 2002.

Lasek S., Matwiejszyn, A. \& M. Ptak: Completing exploitation with hydraulic backfilling in conditions of coexisting natural hazards: A case study. Proceedings of the 5th International Symposium on Rockburst and Seismicity in Mines (RaSiM5)-2001, Johannesburg, South Africa, September 17-20, 2001 (Edited by G. Aswegen, A.J. Durrheim \& W.D. Ortlepp), pp. 343-349. The South African Institute of Mining and Metallurgy, Johannesburg, 2001

Knothe S., 1984, Prognozowanie wplywów eksploatacji górniczej, Katowice, Wydawnictwo „Śląs”” (in Polish).

Kwaśniewski M.: Numerical analysis of strata behavior in the vicinity of a longwall panel in a coal seam mined with roof caving. In Proceedings of the 1st International FLAC/DEM Symposium on Continuum and Distinct Element Numerical Modeling in Geo-Engineering - 2008, Minneapolis, Minnesota, August 25-27, 2008 (Edited by R. Hart, C. Detournay \& P. Cundall), Paper No. 07-08. Itasca Consulting Group, Inc., Minneapolis 2008. (CD-ROM)

Salamon M. D. G., 1968, Elastic moduli of a stratified rock mass. Int. J. Rock Mech. Min. Sci., Vol. 5, pp. 519-527.

Wardle L. J. and Gerrard C. M., 1972, The "equivalent" anisotropic properties of layered rock and soil masses. Rock Mech., Vol. 4, pp.155-175. 